\title{
UPAYA PENGENDALIAN TEKANAN DARAH PADA PENDERITA HIPERTENSI MELALUI GUIDED IMAGERY DI KELURAHAN BINTARO KOTA MATARAM \\ (ARTIKEL EDISI JULI /GENAP)
}

\author{
Dewi Nur Sukma Purqoti ${ }^{1}$, Baik Heni Rispawati ${ }^{2}$, Harlina Putri Rusiana ${ }^{3}$, Ernawati ${ }^{4}$, \\ Baiq Rulli Fatmawati ${ }^{5}$, Marthilda Suprayitna ${ }^{6}$ \\ 1,2,3,4,5,6 Departmen Keperawatan, STIKES YARSI Mataram \\ purqotidewi87@gmail.com
}

\begin{tabular}{|c|c|}
\hline Artic & bstract \\
\hline $\begin{array}{l}\text { Article History } \\
\text { Received: } \\
\text { Revised: } \\
\text { Published: }\end{array}$ & \multirow{2}{*}{$\begin{array}{l}\text { Hypertension or high blood pressure is a disease of the heart and blood vessels } \\
\text { characterized by an increase in systolic blood pressure of more than } 140 \mathrm{mmHg} \text { and } \\
\text { diastolic more than } 90 \mathrm{mmHg} \text { which can result in increased morbidity and mortality. } \\
\text { Hypertension is commonly found in the elderly, hypertension can be treated using } \\
\text { pharmacology and non-pharmacology, one of which is the Guided Imagery technique. } \\
\text { The purpose of this service activity is to increase public knowledge about the basic } \\
\text { concepts of hypertension and how to control it. The method used in this activity is to } \\
\text { provide counseling on the basic concepts of hypertension and how to control it in non- } \\
\text { pharmacological form in the form of Guided Imagery technique. The results of this } \\
\text { activity obtained that the majority of participants were over } 50 \text { years of age, mostly } \\
\text { elementary school education, the sex of the majority of women there was an increase in } \\
\text { knowledge after health education. After the implementation of this service, it is hoped } \\
\text { that the community will carry out the Guided Imagery technique routinely to control } \\
\text { blood pressure and the introduction of non-pharmacological management should be } \\
\text { carried out as a preventive for hypertension in the community. }\end{array}$} \\
\hline $\begin{array}{l}\text { Keywords } \\
\text { Hypertension, } n \\
\text { pharmacology, } \\
\text { Imagery }\end{array}$ & \\
\hline Info & \\
\hline Dipublikasi: & \multirow{2}{*}{$\begin{array}{l}\text { Hipertensi atau tekanan darah tinggi merupakan penyakit kelainan jantung dan } \\
\text { pembuluh darah yang ditandai dengan peningkatan tekanan darah sistolik lebih dari } \\
140 \text { mmHg dan diastolik lebih dari } 90 \mathrm{mmHg} \text { yang dapat mengakibatkan peningkatan } \\
\text { angka kesakitan (morbiditas) dan angka kematian (mortalitas). Hipertensi banyak } \\
\text { ditemukan pada lansia, hipertensi dapat diatasi menggunakan farmakologi dan } \\
\text { nonfarmakologi salah satunya dengan teknik Guided Imagery. Tujuan dari kegiatan } \\
\text { pengabdian ini untuk meningkatkan pengetahuan masyarakat tentang konsep dasar } \\
\text { Hipertensi dan cara pengendaliannya. Metode yang dikukan dalam kegiatan ini } \\
\text { dengan memberikan penyuluhan tentang konsep dasar Hipertensi dan cara } \\
\text { pengendaliannya dalam bentuk non farmakologi berupa teknik Guided Imagery. Hasil } \\
\text { dari kegiatan ini didapatkan peserta mayoritas berusia diatas } 50 \text { tahun, berpendidikan } \\
\text { mayoritas SD, jenis kelamin mayoritas perempuan terdapat peningkatan pengetahuan } \\
\text { setelah dilakukan penyuluhan kesehatan. Setelah pelaksanaan kegiatan pengabdian ini } \\
\text { diharapkan masyarakat melaksanakan teknik Guided Imagery secara rutin untuk } \\
\text { mengendalikan tekanan darah dan hendaknya dilaksanakan pengenalan tatalaksana } \\
\text { non farmakologi sebagai preventif kejadian Hipertensi di masyarakat. }\end{array}$} \\
\hline $\begin{array}{l}\text { Kata kunci } \\
\text { Hipertensi, } \\
\text { farmakologi, } \\
\text { Imagery }\end{array}$ & \\
\hline
\end{tabular}

\section{PENDAHULUAN}

Sehat merupakan hak setiap orang, setiap orang mempunyai hak yang sama dalam memperoleh pelayanan akses atas sumber daya di bidang kesehatan yang aman dan bermutu, serta berhak secara mandiri dan bertanggung jawab menentukan sendiri pelayanan kesehtan kesehatan yang di perlukan bagi dirinya. Hal ini dilakukan agar terwujud derajat kesehatan masyarakat yang optimal. Sri Sumartini (2016).

Seseorang dinyatakan mengidap hipertensi bila tekanan darahnya $\geq 140 / 90$ mmHg.Hipertensi adalah suatu keadaan di mana seseorang mengalami peningkatan tekananan darah 
di atas normal yang mengakibatkan peningkatan angka kesakitan (Morbiditas) dan angka kematian (Mortalitas). Hipertensipada umumnya tidak mempunyai penyebab yang spesifik.Hipertensi terjadi sebagai respon peningkatan cardiac output atau peningkatan tekanan kapiler. Namun ada beberapa faktor yang mempengaruhi terjadinya hipertensi yaitu genetic, obesitas,stress karena lingkungan, hilang elastisitas jaringan dan arterisklerosis pada orang tua serta pelebaran pembuluh darah. Penyebab hipertensi pada orang lanjut usia dalah terjadinya perubahan-perubahan pada elastisitas dinding aorta menurun, katub jantung menebal dan menjadi kaku, kemampuan jantung memompa darah menurun.

Hipertensi termasuk masalah yang besar dan serius karena sering tidak terdeteksi meskipun bertahun-tahun. Ketika gejala timbul, hipertensi sudah menjadi penyakit yang harus diterapi seumur hidup, pengobatan yang harus di keluarkan cukup mahal dan membutuhkan waktu yang lama. Bila tidak ditangani dengan baik akan menimbulkan masalah lain berupa komplikasi berbagai organ jantung, ginjal, otak, mata. Hipertensi juga dapat menyebabkan kecacatan permanen dan kematian mendadak.Penyakit hipertensi pada lansia memerlukan penangan tanpa menimbulkan efek samping yang bertujuan untuk mencegah terjadinya morbiditas dan mortalitas serta mem pertahankan tekanan darah normal. Sri Sumartini (2016).

Berdasarkan data WHO (World Health Organization) dari 70\% penderita hipertensi yang diketahui hanya $25 \%$ yang mendapat pengobatan, dan hanya $12,5 \%$ yang diobati dengan baik. Diperkirakan sampai tahun 2025 tingkat terjadinya tekanan darah tinggi akan bertambah 60\%, dan akan mempengaruhi 1,56 milyar penduduk di seluruh dunia (Depkes RI, 2016). Hasil Riset Kesehatan Dasar (Riskesdas) indonesia tahun 2018 menunjukkan sebagian besar kasus hipertensi di masyarakat belum terdiagnosis. Hal ini terlihat dari hasil pengukuran tekanan darah pada usia $>18$ tahun ditemukan prevalensi hipertensi di indonesia sebesar 34,1\% dimana hanya $7,2 \%$ penduduk yang sudah mengetahui memiliki hipertensi dan hanya $8,8 \%$ kasus yang minum obat hipertensi (Riskesdas, 2018).

Berdasarkan data di Provinsi NTB diperkirakan sebanyak 358.110 jiwa dan yang mendapatkan pelayanan sebesar 56.107 jiwa (15,67\%). Jumlah penderita hipertensi tahun 2018 di puskesmas sekota mataram berjumlah 37.190 kasus (Dikes Prov NTB, 2019). Berdasarkan data yang didapatkan dari Puskesmas Ampenan Kota Mataram di tahun 2017 jumlah penduduk usia $\geq 18$ tahun wilayah puskesmas sebesar 25.253 jiwa, dan yang dilakukan pengukuran tekanan darah sebanyak 6.338 jiwa $(25,10 \%)$. Sedangkan yang menderita hipertensi sebanyak 1.750 kasus $(6,93 \%)$. Kemudian pada tahun 2018 jumlah penduduk usia $\geq 18$ tahun meningkat sebanyak 38.628 jiwa dan yang dilakukan pengukuran tekanan darah sebesar 7.028 jiwa (36,02\%). Sedangkan jumlah penderita hipertensi juga meningkat sebesar 2.610 kasus $(6,76 \%)$ dari tahun lalu. Didapat data bahwa Kelurahan Bintaro merupakan wilayah yang banyak penduduknya menderita hipertensi yaitu sebesar 746 kasus (8,51\%). Sedangkan Kelurahan Dayan Peken 736 kasus (6,92\%), Kelurahan Ampenan Tengah 638 kasus (5,54\%), dan Kelurahan Ampenan Utara 490 kasus (6,36\%). Terdapat dua desa di Kelurahan Bintaro yaitu Pondok Perasi dan Bugis. Data jumlah penderita hipertensi bulan september-november tahun 2019 di Kelurahan Bintaro Desa Pondok Perasi sebanyak 60 orang, sedangkan di Desa Bugis sebanyak 20 orang.

Pengelolaan hipertensi bisa dilakukan dengan metode farmakologi atau obat-obatan dan non farmakologi. Metode farmakologi yaitu dengan obat antihipertensi. Sedangkan Manajemen non farmakologi salah satunya dapat dilakukan dengan teknik guided imagery yaitu teknik relaksasi dengan menggunakan imajinasi seseorang dengan satucara yang dirancang secara khusus untuk mencapai efek tertentu. Pada teknik ini stimulasi otak melalui imajinasi dapat menimbukan pengaruh langsung pada system saraf, endokrin, neuromodulator, endorphin dengan cara mampu menurunkan frekuesi hart rate sehingga cardiac output akan sesuai dengan normal ritme. Yeti Nurhayati (2019).

Berdasarkan hal tersebut di atas maka kami mengadakan kegiatan promosi kesehatan tentang pengenalan dasar tanda dan gejala hipertensi serta pengenalan teknik guided imagery sebagai upaya pengendalian tekanan darah di kelurahan bintaro kota mataram.

\section{METODE PELAKSANAAN}


Kegiatan pengabdian masyarakat ini telah dilaksanakan pada hari senin , 17 Februari 2020 dimulai sejak pukul 08.00- selsai di rumah salah satu kader kesehatan di kelurahan bintaro kota mataram., dengan target sasaran mencapai 16 Orang. Sebelum pelaksanaan kegiatan dilakukan terlebih dahulu observasi lokasi pada tanggal 12 Februari 2020 Persiapan kegiatan dilakukan dengan melakukan koordinasi dengan kepala desa dan ketua RT untuk persiapan tempat pelaksanaan kegiatan.

Salah satu solusi yang cukup strategis yang ditawarkan dalam kegiatan pengabdian ini adalah peningkatan pengetahuan masyarakat tentang konsep dasar hipertensi dan pengenalan teknik teknik guided imagery sebagai upaya non farmakologi untuk pengendalian tekanan darah.

Adapun metode pelaksanaan kegiatan pengabdian ini adalah :

1. Pre Test

Pada tahap ini dilakukan pengkajian terhadap pengetahuan warga tentang penyakit hipertensi dan pengukuran tekanan darah sebelum dilakukan penyuluhan kesehatan dan pelaksanan guided imagery

2. Pemaparan Materi

Pada tahap ini dilakukan pemaparan materi tentang konsep dasar hipertensi, penyebab, tanda dan gejala, cara pencegahan dengan metode ceramah dan diskusi menggunakan media LCD. Setelah pemaparan materi, selanjutnya dilakukan diskusi. Warga dipersilahkan untuk bertanya tentang hal-hal yang belum dipahami terkait materi penyuluhan

3. Pelaksanaan teknik guided imagery

Setelah pemaparan materi selanjutnya dilakukan pelaksanan guided imagery sekitar 15 menit.

4. Post Test

Pada tahap ini dilakukan pengkajian kembali pengetahuan warga mengenai penyakit hipertensi dan pengukuran tekanan darah post perlakuan guided imagery

5. Monitoring dan Evaluasi

Pada tahap ini tim pengabdian masyarakat melakukan evaluasi dan monitoring terhadap Monitoring kembali dilakukan 2 minggu setelah pelaksanaan pengabdian masyarakat.

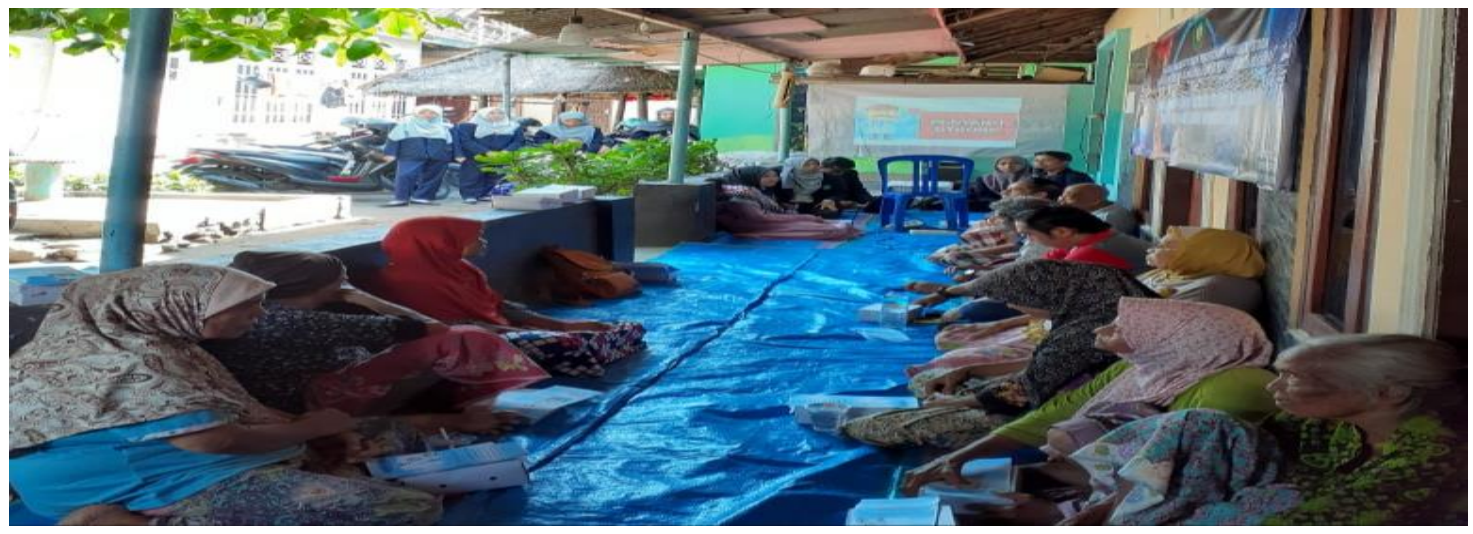

Gambar 1. Proses kegiatan pengabdian 


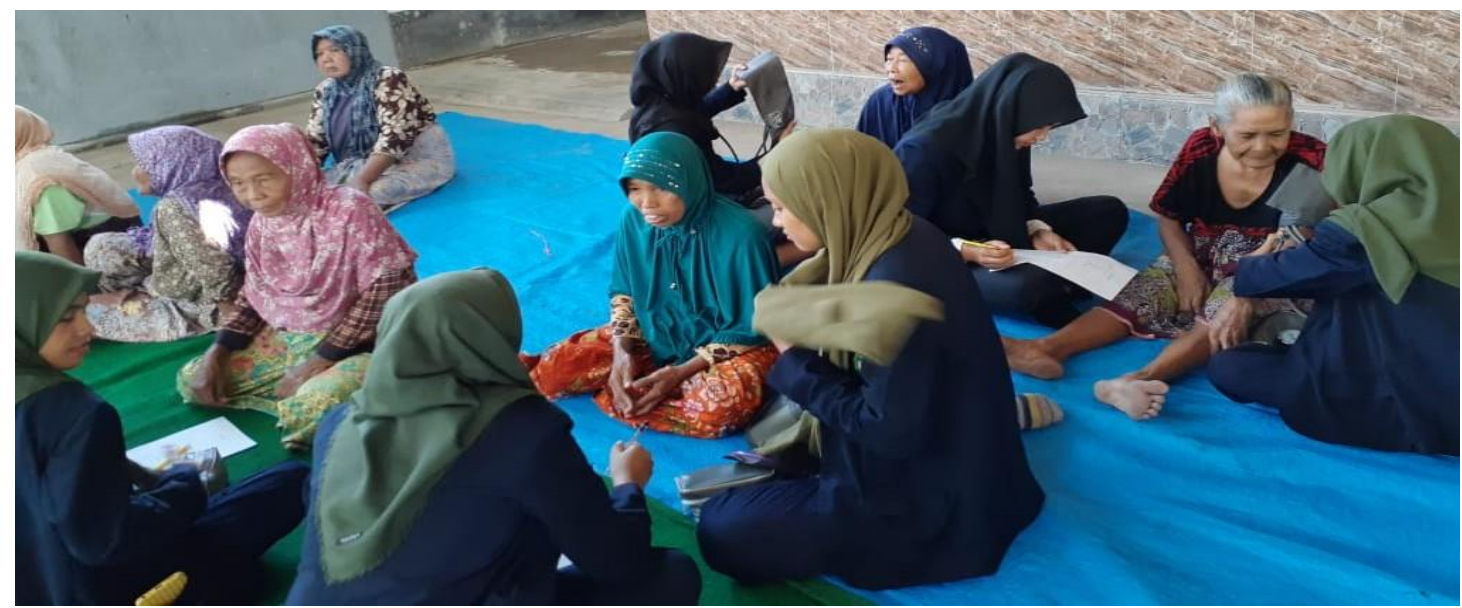

Gambar 2. Pelaksanaan post tes

\section{HASIL DAN PEMBAHASAN}

Kegiatan pengabdian masyarakat ini kami mulai lakukan dengan melakukan persiapan pelaksanaan 1 minggu sebelummnya dengan melakukan koordinasi secara lisan dan surat kepada instansi dan kontak person terkait yaitu kepala lingkungan. Total peserta kegiatan ini adalah 16 peserta. Peserta terdiri dari laki-laki dan perempuan mayoritas peserta berjenis kelamin perempuan, mayoritas peserta berusia diatas 50 tahun berpendidikan mayoritas SD. Serta adanya peningkatan pengetahuan sebelum dan sesudah diberikan penyuluhan kesehatan.

Tabel 1 Distribusi Usia, Jenis kelamin, Pendidikan dan Pengetahuan warga di kelurahan Bintaro kota mataram

\begin{tabular}{|c|c|c|c|}
\hline No & Usia & Frekuensi & $\%$ \\
\hline 1 & $<50$ tahun & 5 & 31,3 \\
\hline \multirow[t]{2}{*}{2} & $\geq 50$ tahun & 11 & 68,7 \\
\hline & Total & 16 & 100 \\
\hline $\mathrm{No}$ & Jenis Kelamin & Frekuensi & $\%$ \\
\hline 1 & Laki-laki & 6 & 37,5 \\
\hline \multirow[t]{2}{*}{2} & Perempuan & 10 & 62,5 \\
\hline & Total & 16 & 100 \\
\hline No & Pendidikan & Frekuensi & $\%$ \\
\hline 1 & SD & 8 & 50 \\
\hline 2 & SMP & 2 & 12,5 \\
\hline 3 & SMA & 4 & 25 \\
\hline \multirow[t]{2}{*}{4} & $\mathrm{~S} 1$ & 2 & 12,5 \\
\hline & Total & 16 & $100 \%$ \\
\hline No & $\begin{array}{l}\text { Pengetahuan } \\
\text { Sebelum }\end{array}$ & Frekuensi & $\%$ \\
\hline 1 & Kurang & 10 & 62,5 \\
\hline 2 & Cukup & 5 & 31,3 \\
\hline \multirow[t]{2}{*}{3} & Baik & 1 & 6,2 \\
\hline & Total & 16 & 100 \\
\hline No & $\begin{array}{l}\text { Pengetahuan } \\
\text { Setelah }\end{array}$ & Frekuensi & $\%$ \\
\hline 1 & Kurang & 4 & 25 \\
\hline 2 & Cukup & 10 & 62,5 \\
\hline \multirow[t]{2}{*}{3} & Baik & 2 & 12,5 \\
\hline & Total & 24 & 100 \\
\hline
\end{tabular}

(sumber: Data primer 2020) 
Kegiatan pengabdian masyrakat ini didominasi oleh responden usia diatas 50 tahun yaitu sebanyak 11 orang. bertambahnya umur dapat meningkatkan resiko hipertensi. Hipertensi bisa terjadi pada pada segala usia, namun paling sering di jumpai pada usia 35tahun atau lebih, hal ini sering disebabkan oleh perubahan alami pada jantung, pembuluh darah dan hormone, hanya saja bila perubahan ini disertai dengan faktor-faktor lain maka memicu terjadinya hipertensi. Hal ini juga sesuai dengan teori yang menyatakan bahwa tekanan darah meningkat sesuai dengan peningkatan usia. Hampir setiap orang mengalami kenaikan tekanan darah ketika uasianya bertamabah. Jadi, semakin tua usianya, kemungkinan menderita hipertensi semakin besar.

Distribusi jenis kelamin responden yang paling banyak adalah jenis kelamin perempuan, yaitu 10 orang. Hal ini sesuai dengan teori bahwa jenis kelamin sangat erat kaitannya terhadap terjadinya hipertensi. Jenis kelamin juga merupakan salah satu faktor yang mempengaruh tekanan darah. Perempuan cendrung menderita hipertensi dari pada laki-laki. Perempuan akan mengalami peningkatan resiko tekanan darah tinggi (hipertensi) setelah menopause yaitu 45 tahun. (Anggraini dkk, 2009) . Hipertensi dapat disebabkan oleh bergam faktor resiko. Berapa faktor resiko hipertensi meliputi usia, jenis kelamin, merokok, stress, dan riwayat hipertensi.

Tekanan darah tinggi merusak arteri di seluruh tubuh, menciptakan kondisi di mana mereka dapat pecah atau menyumbat lebih mudah, tingginya kasus hipertensi sejalan dengan bertambahnya umur yang disebabkan oleh perubahan struktur pada pembuluh darah besar, sehingga pembuluh darah menjadi lebih sempit dan dinding pembuluh darah menjadi kaku, sebagai akibatnya adalah meningkatnya tekanan darah sistolik. Selain usia pra lansia, usia dewasa muda yaitu $>20$ tahun banyak yang mengalami hipertensi. Hal ini dapat dipengaruhi oleh stressor yang tinggi. Selain itu, terdapat faktor lain yang memungkinkan mempunyai efek terhadap bagaimana pasien berespon terhadap stressor yang dialaminya. Dilihat dari Usia responden pada kelompok lansia, semakin cukup usia seseorang maka semakin bayak pengalaman yang dimiliki dalam mengatasi stresor. Pendidikan juga memberikan sumbangsih dalam mengatasi stresor, semakin tinggi pendidikan seseorang maka semakin tinggi pengetahuannya sehingga kemampuan dalam menghadapi masalah, menganalisa situasi, dan pada akhirnya memilih tindakan yang tepat dalam menghadapi suatu masalah (Stuart \& Suddeen, 2006).

Salah satu solusi yang dilakukan pada pengbdian ini berupa Pelaksanaan teknik guided imagery, terapi Guided imagery merupakan teknik penggunaan imajinasi individu yang secara khusus bertujuan untuk mencapai pengendalian dan relaksasi. Dari respon relaksasi tersebut bekerja lebih dominan pada system saraf parasimpatik, sedangkan saraf parasimpatik berfungsi untuk mengendalikan denyut jantung untuk membuat tubuh menjadi rileks. Ketika respon rileksasi dirasakan oleh tubuh, maka secara bersamaan ia akan memperlambat detak jantung sehingga denyutnya dalam memompa darah keseluruh tubuh akan menjadi lebih efektif dan akan mengakibatkan tekanan darah juga dapat menurun. Guided imagery dapat berpengaruh terhadap proses fisiologi tekanan darah Karena relaksasi dengan guided imagery dapat mengaktivasi system saraf parasimpatis.

Pada saat kondisi tubuh sedang rileks tubuh akan mempengaruhi kelenjar pituitary yang akan menghasilkan hormon endorphin. Hormone endorphin merupakan neuromodulator yang bekerja secara tidak langsung dengan menurunkan efek partikuler neurotransmitter. Dalam hal ini, hormone endorphin menurunkan neurotransmitter berupa katekolamin. Penurunan kadar katekolamin dalam pembuluh darah dapat mengakibatkan denyut jantung berkurang dan tekanan darah menjadi turun.

\section{KESIMPULAN}

Berdasarkan kegiatan yang dilakukan, maka dapat disimpulkan sebagai berikut : Peserta kegiatan pengabdian masyarakat mayoritas berusia di atas 50 tahun, dengan jenis kelamin mayoritas perempuan, pendidikan terbanyak adalah SD dan adanya peningkatan pengetahuan setelah dilakukan penyuluhan kesehatan.

\section{SARAN}


Setelah pelaksanaan kegiatan pengabdian ini diharapkan masyarakat melaksanakan teknik Guided imagery secara rutin untuk menjaga tekanan darah tetap stabil dan hendaknya dilaksanakan promosi kesehatan berupa pengenalan tatalaksana non farmakologi yang lain sebagai upaya preventif dalam tatalaksana hipertensi.

\section{DAFTAR PUSTAKA}

Anggraini, Ade, D., Waren, A., Situmorang, E., Asputra \& Siahaan, S. (2009). Faktor-Faktor yang Berhubungan dengan Kejadian Hipertensi pada Pasien yang Berobat di Poliklinik Dewasa Puskesmas Bangkinang. Fakultas Kesehatan. Universitas Riau. Files of DrsMed-FK UNRI : $1-41$

Apiani Reny Yuli. (2014). Asuhan Keperawatan Gerontik. CV Trans Info Media

Dewi, Sofia R. (2014). Buku Ajar Keperawatan Gerontik. Yogyakarta: Deepublish

Dikes Prov. NTB. (2019).A Profil Kesehatan Provinsi Nusa Tenggara Barat Tahun 2018.

Depkes. (2016). Profil kesehatan indonesia 2015. Departemen Kesehatan Republik Indonesia : Jakarta

Kementrian kesehatan republik Indonesia .(2018). http//www.p2ptm.kemkes.go.id Data dan informasi profil kesehatan

Lorna Lolo Lestari, Novianty Nensi (2018)..Pengaruh Pemberian Guided Imagery Terhadap Skala Nyeri Pada Pasien Post Operasi Appendisitis Hari Pertama Di RSUD Sawerigading Kota Palopo. Volume 01. Jurnal Fenomena Kesehatan.

Mahanani Srinalesti, Yusiana Maria Anita.(2017). Terapi Imajinasi terbimbing.Adjie Media Nusantara.

Manuntung Alfeus .(2018). Terapi Prilaku Kognitif pada pasien Hipertensi. Wineka Media

Nurhayati yeti.(2019). Pengeruh Imajinasi Tterbimbing Terhadap Tekananan Darah Penderita Hipertensi di Panti Wirda Ilomata.Vol 1, No 1.Jambura Journal of Health Sciences and Research.

Prasetyaningrum yunita indah .(2014).Hipertensi Bukan untuk ditakuti. Fmedia

Riskesdas. (2018). Riset Kesehatan Dasar 2018. Jakarta : Badan Penelitian dan Pengembangan

Kesehatan, Departemen Kesehatan, Republik Indonesia Stuart dan Sundeen. (2006). Buku saku keperawatan. Edisi 3. Jakarta: EGC

Sumartini Sri, Bachtiar Heru Hari. (2016). Perbedaan Tekanan Darah Sebelum dan Sesudah Pemberian Teknik Relaksasi Imajinasi Terbimbing Pada Lansia Yang Menderita Hipertensi.Vol.2 No.1.Jurnal Keperawatan Indonesia.

Vidi Zahrotul Aisi.(2017).Pengaruh terapi Guided Imagery Terhadap Insomia Pada lansia.

Zohrotul Aisi, Vidi. (2017). Pengaruh Terapi Guided Imagery Terhadap Insomia Pada Lansia.

Skripsi Sarjana Ilmu Keperawatan Insan Cendikia Medika Jombang 